\title{
Modal Simulation of Gearbox Vibration With Experimental Correlation
}

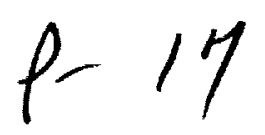

Fred K. Choy and Yeefeng F. Ruan

The University of Akron

Akron, Ohio

and

James J. Zakrajsek and Fred B. Oswald

National Aeronautics and Space Administration

Lewis Research Center

Clevelard, Ohio

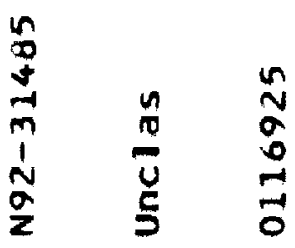

Prepared for the 28th Joint Propulsion Conference and Exhibit cosponsored by the AIAA, SAE, ASME, and ASEE Nashville, Tennessee, July 6-8, 1992 


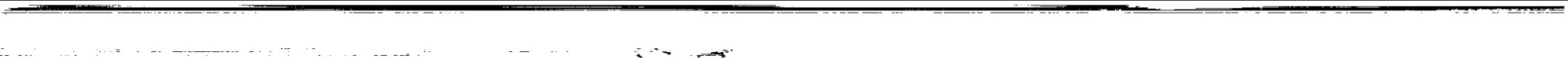

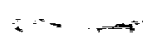

- 


\title{
MODAL SIMULATION OF GEARBOX VIBRATION WITH \\ EXPERIMENTAL CORRELATION
}

\author{
Fred K. Choy, Yeefeng F. Ruan \\ Department of Mechanical Engineering \\ The University of Akron \\ Akron, Ohio 44325 \\ and \\ James J. Zakrajsek, Fred B. Oswald \\ National Aeronautics and Space Administration \\ Lewis Research Center \\ Cleveland, Ohio 44135
}

$\underline{\text { Abstract }}$

A newly developed global dynamic model was used to simulate the dynamics of a gear noise rig at the NASA Lewis Research Center. Experimental results from the test rig were used to verify the analytical model. In this model, the number of degrees of freedom of the system are reduced by transforming the system equations of motion into modal coordinates. The vibration of the individual gear-shaft systems is coupled through the gear-mesh forces. A threedimensional bearing model was used to couple the casing structural vibration to the gear rotor dynamics. The system of modal equations is solved to predict the resulting vibration at several locations on the test rig. Experimental vibration data were measured at several running speeds and were compared to the predictions of the global dynamic model. There was excellent agreement between the analytical and experimental vibration results.

\section{Nomenclature}

\{A\} rotor modal displacement of $\left(X, \theta_{X}\right)$

$\left\{A_{c}\right\} \quad$ casing modal displacement of $\left(X_{c}, X_{c \theta}\right)$

\{B\} rotor modal displacement of $\left(Y, \theta_{y}\right)$
$\left\{B_{c}\right\} \quad$ rotor modal displacement of $\left(Y_{c}, y_{c \theta}\right)$

$\left[\mathrm{C}_{\mathrm{b}}\right]$ bearing damping matrix

$\left[\overline{\mathbf{C}_{b}}\right] \quad[\Phi]^{\mathrm{T}}\left[\mathrm{C}_{\mathrm{b}}\right][\Phi]$

$\left[\overline{\overline{\mathbf{C}}}_{\mathbf{b}}\right] \quad\left[\Phi_{\mathbf{c}}\right]^{\mathbf{T}}\left[\mathbf{C}_{\mathbf{b}}\right]\left[\Phi_{c}\right]$

$\left[\mathrm{C}_{\mathrm{c}}\right]$ casing structure damping matrix

$\left[\bar{C}_{c}\right] \quad\left[\Phi_{c}\right]^{T}\left[C_{c}\right]\left[\Phi_{c}\right]$

\{D\} rotor modal displacement of $\mathrm{Z}$

$\left\{D_{c}\right\} \quad$ casing modal displacement of $\left(Z_{c}, Z_{c \theta}\right)$

$\left\{D_{t}\right\}$ rotor modal displacement of $\theta_{t}$

F gear force

$\{F(t)\} \quad$ external and mass imbalance excitations

$\left\{F_{c}(t)\right\}$ force acting on casing structure

$\left\{F_{G}(t)\right\}$ nonlinear gear forces, through gear mesh coupling

$\left\{F_{g}(t)\right\} \quad$ shaft bow force $=\left[K_{g}\right]\left\{W_{r}\right\}$

$\left[G_{A}\right]$. rotor angular acceleration 
$\left[\bar{G}_{A}\right] \quad[\Phi]^{\mathbf{T}}\left[\mathbf{G}_{\mathbf{A}}\right][\Phi]$

$\left[G_{\mathbf{v}}\right] \quad$ gyroscopic forces

$\left[\bar{G}_{\mathbf{v}}\right] \quad[\Phi]^{\mathbf{T}}\left[\mathrm{G}_{\mathbf{v}}\right][\Phi]$

$\left[\mathrm{K}_{\mathrm{A}}\right] \quad 1 / 2\left\{\left[\mathrm{~K}_{\mathrm{bx}}\right]+\left[\mathrm{K}_{\mathrm{by}}\right]\right\}$

$\left[\bar{K}_{A}\right] \quad[\Phi]^{\mathbf{T}}\left[K_{A}\right][\Phi]$

$\left[\mathrm{K}_{\mathrm{b}}\right]$ bearing axial and lateral cross-coupling stiffness

$\left[\mathbf{K}_{\mathbf{b}}\right] \quad[\Phi]^{\mathbf{T}}\left[\mathbf{K}_{\mathbf{b}}\right][\Phi]$

$\left[\overline{\bar{K}}_{b}\right] \quad\left[\Phi_{c}\right]^{T}\left[K_{b}\right]\left[\Phi_{c}\right]$

$\left[K_{c}\right] \quad$ casing structure stiffness

$\left[\mathrm{K}_{\mathrm{g}}\right]$ shaft bow stiffness

[M] mass matrix of rotor

$\left[\mathrm{M}_{\mathrm{c}}\right] \quad$ mass matrix of casing structure

$\mathbf{R} \quad$ pitch radius of gear

$\{[W]\}$ generalized displacement vector of rotor

$\left\{\left[W_{c}\right]\right\} \quad$ generalized displacement vector of casing

$\left\{W_{\mathbf{r}}\right\} \quad$ genearlized displacement vector of rotor

$\mathrm{X}, \mathrm{Y}, \mathrm{Z}$ displacement vectors

$\alpha \quad$ angle of orientation

$\theta \quad$ Eq. (5)

$\theta \quad$ generalized displacement

$\theta_{t} \quad$ torsional rotational vector

$\theta_{x}, \theta_{y} \quad$ lateral rotational vectors $\mu \quad$ friction coefficient between the gear tooth surface

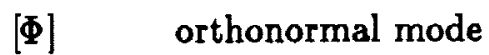

$\left[\Phi_{c}\right]$ orthonormal mode of casing

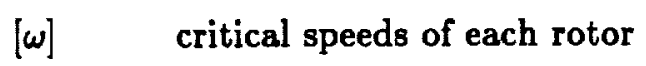

$\left[\omega_{c}\right] \quad$ critical speeds of casing

\section{$\underline{\text { Introduction }}$}

Large vibrations in gear transmission systems causes excessive wear and crack formation in gear teeth, which results in premature gear failure. With the need for higher operating speeds and power from transmission systems, the problem of excessive vibration becomes even more critical.

In order to insure smooth and safe operation, it is necessary to understand the dynamics of the gear transmission system.

Two areas of research in the dynamics of gear transmission systems are (1) analytical simulation and (2) experimental testing. There is a great deal of literature on the vibration analysis of a single gear stage. ${ }^{1-6}$ Some work has been done on multistage gear vibration, ${ }^{7-9}$ but very limited work ${ }^{10-11}$ has been done on the dynamic analysis of gearbox vibration. Considerable effort has been devoted to experimentally studying gear dyanmics ${ }^{12-14}$ and localized vibration effects on gear teeth. ${ }^{15}$ A few studies have been conducted to correlate analytically predicted and experimentally measured gearbox vibrations.

This paper correlates the experimental results obtained from the test rig at the NASA Lewis Research Center with predictions from an analytical model developed by using the modal synthesis method. ${ }^{7}$ The major excitations of the rotor system include mass imbalance, shaft residual bow, nonlinear gear-mesh forces ${ }^{16}$ and gear-tooth frictional effects. ${ }^{14}$ The vibratory motion between the rotor and the casing is coupled 
through the support bearing in the lateral and axial directions. ${ }^{11}$ Gearbox mode shapes and vibration predictions from the analytical model are compared to those obtained from experimental testing.

\section{Analytical Procedure}

\section{Development of Equations of Motion}

The equations of motion for each gear-shaft system can be written in matrix form ${ }^{7}$ as

$$
\begin{aligned}
& {[M]\{\ddot{\mathbf{W}}\}+\left[\mathbf{G}_{\mathbf{v}}\right]\{\dot{\mathbf{W}}\}+\left[\mathbf{G}_{\mathrm{A}}\right]\{\mathbf{W}\}+\left[\mathbf{C}_{\mathbf{b}}\right]\left\{\dot{\mathbf{W}}-\dot{\mathbf{W}}_{\mathrm{c}}\right\}} \\
& \left.+\mid K_{b}\right]\left\{w-w_{c}\right\}+\left[K_{b}\right]\left\{w-W_{r}\right\} \\
& =\{\mathrm{F}(\mathrm{t})\}+\left\{\mathrm{F}_{\mathrm{G}}(\mathrm{t})\right\}
\end{aligned}
$$

where $[M]$ is the mass matrix of the rotor (inertia), $\{\ddot{W}\}$ is the generalized displacement vector consisting of the three displacement vectors $\mathrm{X}, \mathrm{Y}, \mathrm{Z}$ with the corresponding lateral $\theta_{\mathrm{x}}, \theta_{\mathrm{y}}$, and torsional $\theta_{t}$ rotational vectors as

$$
\{\mathrm{W}\}=\left\{\begin{array}{c}
(\mathrm{X}) \\
\left(\theta_{\mathrm{X}}\right) \\
(\mathrm{Y}) \\
\left(\theta_{\mathrm{Y}}\right) \\
(\mathrm{Z}) \\
\left(\theta_{\mathrm{t}}\right)
\end{array}\right\}
$$

and where $\left[G_{v}\right]$ is the gyroscopic force; $\left[G_{A}\right]$ is the rotor angular acceleration; $\left[C_{b}\right]$ is the bearing direct and cross-coupling damping, $\left[K_{b}\right]$ is the bearing axial and lateral cross-coupling stiffness; $^{11}\left\{\mathrm{~W}-\mathrm{W}_{\mathrm{c}}\right\}$ is the casing vibration; $\left[\mathrm{K}_{\mathrm{g}}\right]$ is the shaft bow stiffness; $\left\{W-W_{r}\right\}$ is the shaft residual bow; $\{F(t)\}$ is the external and mass imbalance excitation; and $\left\{\mathrm{F}_{\mathrm{G}}(\mathrm{t})\right\}$ is the nonlinear gear force through gear-mesh coupling.

For a multiple gear-shaft system, the equations of motion (l) are repeated for each shaft.
The motions of the individual shafts are coupled to each other through the gear-mesh forces (Fig. 1) and to the casing through bearing stiffness $\left[K_{b}\right]$ and damping $\left[C_{b}\right]$.

The equations of motion for the casing can be written as

$$
\begin{aligned}
{\left[\mathrm{M}_{c}\right]\left\{\ddot{\mathrm{W}}_{\mathrm{c}}\right\}+\left[\mathrm{C}_{\mathrm{b}}\right]\left\{\dot{\mathrm{W}}_{\mathrm{c}}-\dot{\mathrm{W}}\right\}+\left[\mathrm{K}_{\mathrm{b}}\right]\left\{\mathrm{w}_{\mathrm{c}}-\mathrm{W}\right\} } \\
+\left[\mathrm{C}_{\mathrm{c}}\right]\left\{\dot{\mathrm{W}}_{\mathrm{c}}\right\}+\left[\mathrm{K}_{\mathrm{c}}\right]\left\{\mathrm{W}_{\mathrm{c}}\right\}=\left\{\mathrm{F}_{\mathrm{c}}(\mathrm{t})\right\}
\end{aligned}
$$

where $\left[M_{c}\right]$ is the mass matrix of the casing structure; $\left\{W_{c}\right\}$ represents the generalized displacement vector of the casing structure:

$$
\left\{W_{c}\right\}=\left\{\begin{array}{l}
\left(\mathrm{X}_{\mathrm{c}}\right) \\
\left(\mathrm{X}_{\mathrm{c} \theta}\right) \\
\left(\mathrm{Y}_{\mathrm{c}}\right) \\
\left(\mathrm{Y}_{\mathrm{c} \theta}\right) \\
\left(\mathrm{Z}_{\mathrm{c}}\right) \\
\left(\mathrm{Z}_{\mathrm{c} \theta}\right)
\end{array}\right\}
$$

$\left[\mathrm{C}_{\mathrm{c}}\right]$ is the casing structure damping matrix; $\left[\mathrm{K}_{\mathrm{c}}\right]$ is the casing structure stiffness; and $\left\{\mathrm{F}_{\mathrm{c}}(\mathrm{t})\right\}$ is the force acting on the casing structure. The nonlinear gear forces for the $\mathbf{k}^{\text {th }}$ individual gearshaft system, using nonlinear gear stiffness ${ }^{16}$ and gear-tooth friction, ${ }^{14}$ are given as $\mathrm{x}$-force

$$
\begin{array}{r}
F_{\text {Gxk }}=\sum_{\mathrm{i}=\mathbf{1}, \mathrm{i} * \mathrm{k}}^{\mathrm{n}} \mathrm{K}_{\mathrm{tkj}}\left[-\mathrm{R}_{\mathrm{ci}} \theta_{\mathrm{ci}}-\mathrm{R}_{\mathrm{ck}} \theta_{\mathrm{ck}}\right. \\
+\left(\mathrm{X}_{\mathrm{ci}}-\mathrm{X}_{\mathrm{ck}}\right) \cos \alpha_{\mathrm{ki}} \\
\left.+\left(\mathrm{Y}_{\mathrm{ci}}-\mathrm{Y}_{\mathrm{ck}}\right) \sin \alpha_{\mathrm{ki}}\right] \\
{\left[\cos \alpha_{\mathbf{k i}}+(\operatorname{sign})(\mu)\left(\sin \alpha_{\mathrm{ki}}\right)\right]}
\end{array}
$$

$y$-force 


$$
\begin{array}{r}
F_{G y k}=\sum_{i=1, i \neq k}^{n} K_{t k i}\left[-R_{c i} \theta_{c i}-R_{c k} \theta_{c k}\right. \\
+\left(X_{c i}-X_{c k}\right) \cos \alpha_{k i} \\
\left.+\left(Y_{c i}-Y_{c k}\right) \sin \alpha_{k j}\right] \\
\\
{\left[\sin \alpha_{k j}+(\operatorname{sign})(\mu)\left(\cos \alpha_{k i}\right)\right]}
\end{array}
$$

and torsional

$$
\begin{array}{r}
F_{\text {Gtk }}=\sum_{i=1, i \neq k}^{n} R_{c k}\left\{K _ { t k j } \left[\left(-R_{c i} \theta_{c i}-R_{c k} \theta_{c k}\right)\right.\right. \\
+\left(X_{c i}-X_{c k}\right) \cos \alpha_{k i} \\
\left.\left.+\left(Y_{c i}-Y_{c k}\right) \sin \alpha_{k i}\right]\right\}
\end{array}
$$

where $R$ is the pitch radius of the gear and $\mu$ is the coefficient of friction between the gear tooth surface and "SIGN" is the unity sign function to provide the sign change when the mating teeth pass the pitch point. ${ }^{14}$

\section{Modal Transformation}

The equation of motion for the undamped rotor system is

$$
[\mathbf{M}]\{\overline{\mathbf{W}}\}+\left[\left[\mathbf{K}_{\mathbf{s}}\right]+\left[\mathbf{K}_{\mathbf{A}}\right]\right]\{\mathbf{W}\}=0
$$

with the average bearing support stiffness from the $x-y$ direction ${ }^{7}$ given as

$$
\left[\mathrm{K}_{\mathrm{A}}\right]=\frac{1}{2}\left\{\left[\mathrm{~K}_{\mathrm{bx}}\right]+\left[\mathrm{K}_{\mathrm{by}}\right]\right\}
$$

The orthogonality condition for the orthonormal modes $[\Phi]$ are

$$
[\Phi]^{\mathbf{T}}[\mathbf{M}][\mathbf{\Phi}]=[\mathrm{I}]
$$

and

$$
[\Phi]^{T}\left[K_{s}+K_{A}\right][\Phi]=\left[\omega^{2}\right]
$$

where $\omega$ is the rotor critical speed. Similarly, a set of orthogonality conditions can be derived for the casing equation of

$$
\left[\mathrm{M}_{\mathrm{c}}\right]\left\{\ddot{\mathrm{W}}_{\mathrm{c}}\right\}+\left[\mathrm{C}_{\mathrm{c}}\right]\left\{\dot{\mathrm{W}}_{\mathrm{c}}\right\}+\left[\mathrm{K}_{\mathrm{c}}\right]\left\{\mathrm{W}_{\mathrm{c}}\right\}=0
$$

with the orthonormal mode $\left[\Phi_{c}\right]$ such that

$$
\begin{aligned}
& {\left[\Phi_{c}\right]^{T}\left[M_{c}\right]\left[\Phi_{c}\right]=[I]} \\
& {\left[\Phi_{c}\right]^{T}\left[C_{c}\right]\left[\Phi_{c}\right]=\left[C_{c}\right]} \\
& {\left[\Phi_{c}\right]^{T}\left[K_{c}\right]\left[\Phi_{c}\right]=\omega_{c}^{2}}
\end{aligned}
$$

where $\omega_{c}$ is the casing critical speed. Using modal transformation ${ }^{17}$ by letting

$$
\{W\}=\left\{\begin{array}{l}
{\left[\Phi_{x}\right]\{A\}} \\
\left.\Phi_{x \theta}\right]\{A\} \\
{\left[\Phi_{y}\right]\{B\}} \\
{\left[\Phi_{y \theta}\right\}\{B\}} \\
{\left[\Phi_{z}\right]\{D\}} \\
{\left[\Phi_{t}\right]\left\{D_{t}\right\}}
\end{array}\right\}
$$

and

$$
\left\{W_{c}\right\}=\left\{\begin{array}{l}
{\left[\Phi_{c x}\right]\left\{A_{c}\right\}} \\
{\left[\Phi_{c x \theta}\right]\left\{A_{c}\right\}} \\
{\left[\Phi_{c y}\right]\left\{B_{c}\right\}} \\
{\left[\Phi_{c y \theta}\right]\left\{B_{c}\right\}} \\
{\left[\Phi_{c z}\right]\left\{D_{c}\right\}} \\
{\left[\Phi_{c z \theta}\right]\left\{D_{c}\right\}}
\end{array}\right\}
$$

the equations of motion for the rotor (Eq. (1)) can be transformed as 


$$
\begin{aligned}
& {[\mathbf{I}]\{\ddot{\mathbf{Z}}\}+\left[\overline{\mathbf{G}}_{\mathbf{v}}\right]\{\dot{\mathbf{Z}}\}+\left[\overline{\mathbf{G}}_{\mathbf{A}}\right]\{\mathbf{Z}\}+\left[\overline{\mathbf{C}}_{\mathbf{b}}\right]\{\dot{\mathbf{Z}}\}} \\
& -\left[\mathbf{K}_{b}-\mathbf{K}_{\mathbf{A}}\right]\{\mathbf{Z}\}+[\Phi]^{\mathbf{T}}\left[\mathbf{C}_{\mathbf{b}}\right]\left[\Phi_{c}\right]\left\{\dot{\mathbf{Z}}_{\mathbf{c}}\right\} \\
& +\left[\omega^{2}\right]\{Z\}-[\Phi]^{\mathbf{T}}\left[K_{b}\right]\left[\Phi_{c}\right]\left\{Z_{c}\right\} \\
& =[\Phi]^{\mathrm{T}}\left\{\mathrm{F}(\mathrm{t})+\mathrm{F}_{\mathrm{G}}(\mathrm{t})+\mathrm{F}_{\mathrm{s}}(\mathrm{t})\right\}
\end{aligned}
$$

and for the casing (Eq. (3)) as

$$
\begin{aligned}
& {[\mathbf{I}]\left\{\tilde{\mathbf{Z}}_{\mathrm{c}}\right\}+\left[\overline{\mathbf{C}}_{\mathrm{c}}\right]\left\{\dot{\mathbf{Z}}_{\mathrm{c}}\right\}+\left[\omega_{\mathrm{c}}^{2}\right]\left\{\mathbf{Z}_{\mathrm{c}}\right\}} \\
& +\left[\overline{\mathbf{K}}_{\mathrm{b}}\right]\left\{\mathbf{Z}_{\mathrm{c}}\right\}+\left[\overline{\mathrm{C}}_{\mathrm{b}}\right]\left\{\dot{\mathrm{Z}}_{\mathrm{c}}\right\}-\left[\Phi_{\mathrm{c}}\right]^{\mathrm{T}} \\
& {\left[\mathrm{K}_{\mathbf{b}}\right][\Phi]\{\mathbf{Z}\}-\left[\Phi_{\mathrm{c}}\right]^{\mathbf{T}}\left[\mathrm{C}_{\mathbf{b}}\right][\Phi]\{\dot{\mathbf{Z}}\}} \\
& =\left[\Phi_{\mathrm{c}}\right]^{\mathrm{T}}\left\{\mathrm{F}_{\mathrm{c}}(\mathrm{t})\right\}
\end{aligned}
$$

where

$$
\{Z\}=\left\{\begin{array}{c}
\{A\} \\
\{B\} \\
\{D\} \\
\left\{D_{t}\right\}
\end{array}\right\} \quad\left\{Z_{c}\right\}=\left\{\begin{array}{c}
\left\{A_{c}\right\} \\
\left\{B_{c}\right\} \\
\left\{D_{c}\right\}
\end{array}\right\}
$$

\section{Experimental Study}

The gear noise rig (Fig. 2) was used to measure the vibration, dynamic load, and noise of a geared transmission. The rig features a simple gearbox (Fig. 3) containing a pair of parallel axis gears supported by rolling element bearings. A 150-kW (200-hp), variable-speed electric motor powers the rig at one end, and an eddy-current dynamometer applies power-absorbing torque at the other end. The test gear parameters are given in Table 1.

Two sets of experiments were performed on the gearbox; (1) experimental modal analysis and (2) dynamic vibration measurements during operation. In the experimental modal analysis, modal parameters, such as system natural frequencies and their corresponding mode shapes, were obtained through transfer function measurements by using a two-channel, dynamic signal analyzer and modal analysis software. For this experiment, 116 nodes were selected on the gearbox housing. The measured three-dimensional mode shapes are presented in Fig. 4. The dynamic vibration measurements consist of data collected from accelerometers placed at three of the nodes on the surface of the casing. They were chosen such that vibration was measured in all three directions, $X, Y$, and $Z$. A dynamic signal analyzer was used to compute the frequency spectra of the vibration. The experimental frequency spectira are shown in Figs. 5(a), 6(a), and 7(a) for the $\mathrm{X}$-, Y-, and Z-directions, respectively, at a number of different operating speeds.

\section{Discussion and Correlation of Results}

The measured mode shapes, shown in Fig. 4 represent the major vibration modes of the gear noise rig in the $0-$ to $3-\mathrm{kHz}$ region. Although these modes are only a small portion of the total modes of the system, they represent the major portion of the total global vibration of the system. In order to produce a compatible analytical simulation of the test apparatus, a similar set of modes was predicted by a finite-element model of the gearbox structure. This model serves as the basis for predicting casing vibrations in the overall global dynamic model. Of the $\mathbf{2 5}$ modes found by the analytical model in the 0 - to $3-\mathrm{kHz}$ frequency region, the 8 dominant modes were used to represent the gearbox dynamic characteristics. These simulated modes are shown in Fig. 8. The natural frequencies of the predicted modes are within 5 percent of the measured modes (Table 2). Also, the predicted mode shapes are very similar to the experimental modes shapes (Fig. 4). The good correlation of between the analytical model and the measurements confirms the accuracy of the dynamic representation of the test gearbox using only a limited number of modes.

For the dynamic study of the gearbox vibration, it was found that during a slow roll (lowspeed run) of the gear-rotor assembly, a substantial residual bow (or eccentricity in the sleeve assembly) exists in the rotor system as shown by its large orbital motion in Fig. 9. Figure 9(a) 
represents the orbit of the driver rotor at the gear location, and Fig. 9(b) represents that of the driven rotor. Note that the circular orbit in the driver rotor at low speed represents the residual bow deformation of the rotor. The elliptical orbit in the driven rotor is attributed to a combination of the residual bow effects and the vertical gear force from the torque of the driving rotor. In order to analytically simulate the influence of this effect, a residual bow of 2 mils $(0.05 \mathrm{~mm})$ is incorporated into the numerical model (Eq. (1)).

The frequency spectra of the analytically predicted casing vibration in the $\mathrm{X}-,, \mathrm{Y}-$, and $\mathrm{Z}$ directions are presented in Figs. 5(b), 6(b), and 7 (b), respectively. As seen in Fig. 5(a), the experimental casing vibration in the $\mathrm{X}$-direction shows a major vibration component at the gearmesh frequency ( 28 times shaft speed) at each rotational speed. A closer examination of this excited frequency component shows that two major vibration peaks occur at the running speeds of $1500 \mathrm{rpm}$ (at a tooth pass frequency of $700 \mathrm{~Hz}$ ) and $5500 \mathrm{rpm}$ (at a tooth pass frequency of $2560 \mathrm{~Hz}$ ). These peaks are a result of the tooth pass frequency exciting two of the major natural frequencies of the housing, namely the 658- and 2536- $\mathrm{Hz}$ modes. The presence of other modes can be seen; however, the 658- and 2536- $\mathrm{Hz}$ modes, when excited by the gear-mesh frequency, dominate the spectra.

Comparing the predicted vibration spectra with the measured spectra reveals that, although the actual amplitude values did not always agree, the general trends of the spectra were very similar. The predicted vibration spectra of the housing in the X-direction is shown in Fig. 5(b). A comparison of Figs. 5(a) and (b) shows that the predicted amplitude at the gear-mesh frequency at $1500 \mathrm{rpm}$ is only 3 percent above the measured value. The comparison at $5500 \mathrm{rpm}$ is not that close; the predicted amplitude is 38 percent below the measured value. If trends are compared, the predicted spectra show the same gear-mesh, frequency-induced excitation of the 658- and 2536- $\mathrm{Hz}$ modes as that found in the measured spectra at the running speeds of 1500 and 5500 rpm, respectively.

Figures 6 and 7 compare the predicted measured housing vibration spectra in the $\mathrm{Y}$ - and $\mathrm{Z}$ directions, respectively. The results of the comparison are the same as those presented for the housing vibration in the $\mathrm{X}$-direction (Figs. 5(a) and (b)). Acutal values of the components in the spectra were not always in good agreement; however, the general trends for the predicted and measured housing vibration spectra were very similar. Also, as seen in Fig. 7(b) at the 1500-rpm speed, the model predicts the second and third harmonics of the gear-mesh frequency. As shown in Fig. 7(a), the measured vibration confirms the presence of these two harmonics at the 1500-rpm running speed.

\section{Conclusions}

A newly developed global dynamic model was used to simulate the dynamics of a simple transmission system. Predicted casing vibrations were compared to measured results from the gear noise test rig at the NASA Lewis Research Center. The conclusions of this study are summarized as follows:

1. The dynamics of the housing can be accurately modeled with a limited amount of analytically predicted, experimentally verified vibration modes of the structure.

2. The global dynamic model is capable of including in the analysis the effects of shaft residual bow or eccentricity.

3. Absolute values of the housing vibration predicted by the global dynamic model did not always agree with measured values.

4. The characteristics and trends of the housing vibration spectra predicted by the global dynamic model are the same or very similar to those found in the experimental data. 


\section{References}

1. August, R., and Kasuba, R., "Torsional Vibrations and Dynamic Loads in a Basic Planetary Gear System", Journal of Vibration, Acoustic, Stress, and Reliability in Design, Vol. 108, No. 3, July 1986, pp. 348-353.

2. Choy, F.K., Townsend, D.P., and Oswald, F.B., "Dynamic Analysis of Multimesh-Gear Helicopter Transmissions", NASA TP-2789, 1988.

3. Cornell, R.W., "Compliance and Stress Sensitivity of Spur Gear Teeth," Journal of Mechanical Design, Vol. 103, No. 2, Apr. 1981, pp. 447-459.

4. Lin, H., Houston, R.L. and Coy, J.J., "On Dynamic Loads in Parallel Shaft Transmissions 1: Modelling and Analysis," NASA TM-100108, December 1987.

5. Mark, W.D., "The Transfer Function Method for Gear System Dynamics Applied to Conventional and Minimum Excitation Gear Designs”, NASA CR-3626, 1982.

6. Boyd, L.S., and Pike, J., "Epicyclic Gear Dynamics," AIAA Paper 87-2042, June 1986.

7. Choy, F.K., Tu, Y.K., Savage, M., and Townsend, D.P., "Vibration Signature Analysis of Multistage Gear Transmission", Journal of the Franklin Institute, Vol. 328, No. 2/3, 1991, pp. 281-299.

8. David, J.W., Mitchell, L.D., and Daws, J.W., "Using Transfer Matrices for Parametric System Forced Response", Journal of Vibration, Acoustics, Stress and Reliability in Design, Vol. 109, No. 4, Oct. 1987, pp. 356-360.

9. Ozguven, H.N., and Houser, D.R., "Mathematical Models Used in Gear Dynamics-A
Review", Journal of Sound and Vibration, Vol. 121, No. 3, Mar. 22, 1988, pp. 383-411.

10. Choy, F.K., Ruan, Y.F., Zakrajsek, J.J., Oswald, F.B., and Coy, J.J., "Analytical and Experimental Study of Vibrations in a Gear Transmission”, AIAA Paper-91-2019, June 1991.

11. Lim, T.C., Signh, R., and Zakrajsek, J.J., "Modal Analysis of Gear Housing and. Mounts", International Modal Analysis Conference, 7th, Vol. 2, Society of Experimental Mechanics, Bethel, CT, 1990, pp. 1072-1078.

12. Lewicki, D.G., and Coy, J.J., "Vibration Characteristics of the OH-58A Helicopter Main Rotor Transmission", NASA TP-2705, 1987.

13. Oswald, F.B., "Gear Tooth Stress Measurements on the UH-60A Helicopter Transmission", NASA TP-2698, 1987.

14. Rebbechi, B., Oswald, F.O., and Townsend, D.P., "Dynamic Measurements of Gear Tooth Friction and Load", NASA TM-103281, 1991.

15. Townsend, D.P., and Bamberger, E.N., "Surface Fatigue Life of M50NiL and AISI9310 Spur Gears and R C Bars", NASA TM-104496, 1991.

16. Boyd, L.S., and Pike, J.A., "Epicyclic Gear Dynamics", AIAA Journal, Vol. 27, No. 5, May 1989, pp. 603-609.

17. Choy, F.K., Townsend, D.P., and Oswald, F.B., "Experimental and Analytical Evaluation of Dynamic Load and Vibration of a 2240-KW Rotor craft Transmission", Journal of The Franklin Institute, Vol. 326, No. 5, 1989, pp. 721-735. 
TABLE I. - TEST GEAR PARAMETERS

Gear type .......... Standard involute, full-depth tooth Number of teeth $\ldots \ldots \ldots \ldots \ldots \ldots \ldots \ldots \ldots \ldots 28$

Module, $\mathrm{mm}$ (diametrial pitch in. ${ }^{-1}$ ) $\ldots \ldots \ldots \ldots \ldots .174(8)$

Face width, $m m$ (in.) . . . . . . . . . . . . . . .

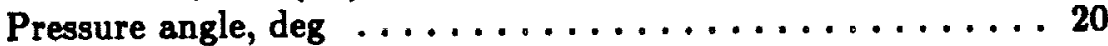

Theoretical contact ratio .................. 1.64

Driver modification amount, $\mathrm{mm}$ (in.) . . . . . . $0.023(0.0009)$

Driven modification amount, $\mathrm{mm}$ (in.) $\ldots \ldots \ldots .0 .025(0.0010)$

Driver modification start, deg . . . . . . . . . . . . 24

Driven modification start, $\operatorname{deg} \ldots \ldots \ldots \ldots \ldots \ldots .24$

Tooth-root radius, $\mathrm{mm}$ (in.) $\ldots \ldots \ldots \ldots \ldots \ldots$ 1.35(0.053)

Gear quality .................. AGMA class 13

Nominal (100 percent) torque, $\mathrm{N}-\mathrm{m}$ (in.-lb) . ... 71.77(635.25)

TABLE 2.-COMPARISON OF

EXPERIMENTAL MEASURED

AND ANALYTICAL MODELED

NATURAL FREQUENICES

\begin{tabular}{|c|c|c|}
\hline $\begin{array}{c}\text { Experimental, } \\
\mathrm{Hz}\end{array}$ & $\begin{array}{c}\text { Analytical, } \\
\mathrm{Hz}\end{array}$ & $\begin{array}{c}\text { Difference, } \\
\text { percent }\end{array}$ \\
\hline 658 & 658 & 0 \\
1049 & 1006 & -4.1 \\
1710 & 1762 & 3.0 \\
2000 & 2051 & 2.6 \\
2276 & 2336 & 2.6 \\
2536 & 1536 & 0 \\
2722 & 2752 & 1.1 \\
2962 & 3012 & 1.7 \\
\hline
\end{tabular}




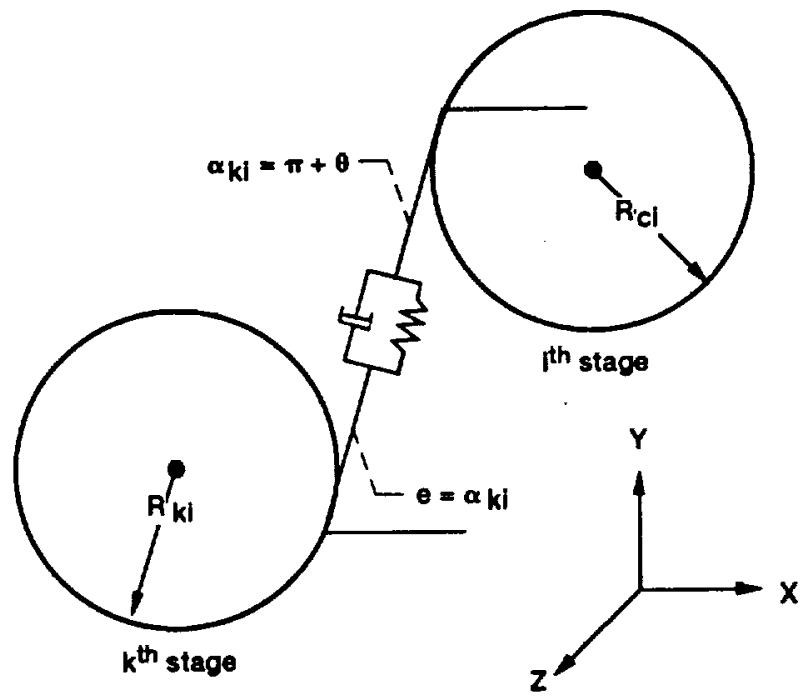

Flgure 1.-Geometry of gear force simulation.

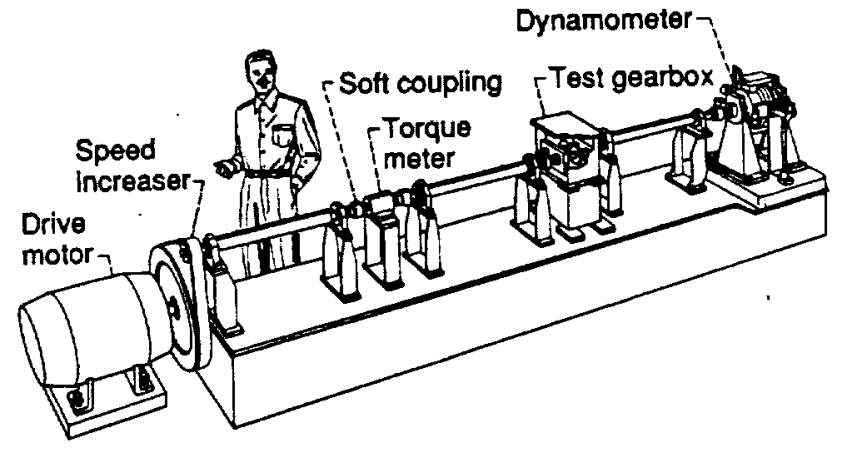

Figure 2.-Picture of gear nolse rig.

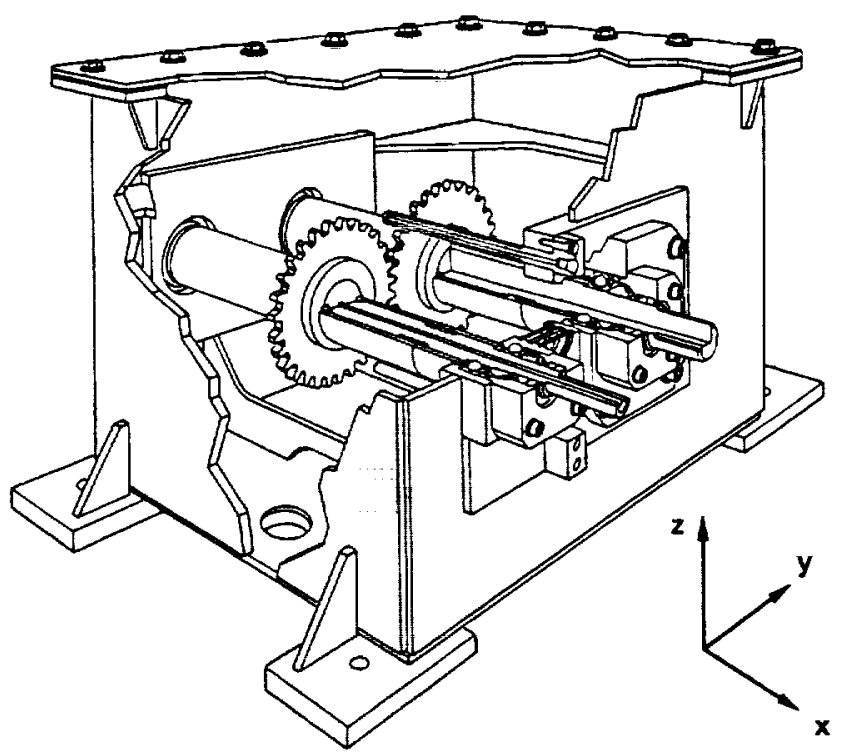

Figure 3.-Test gearbox. 

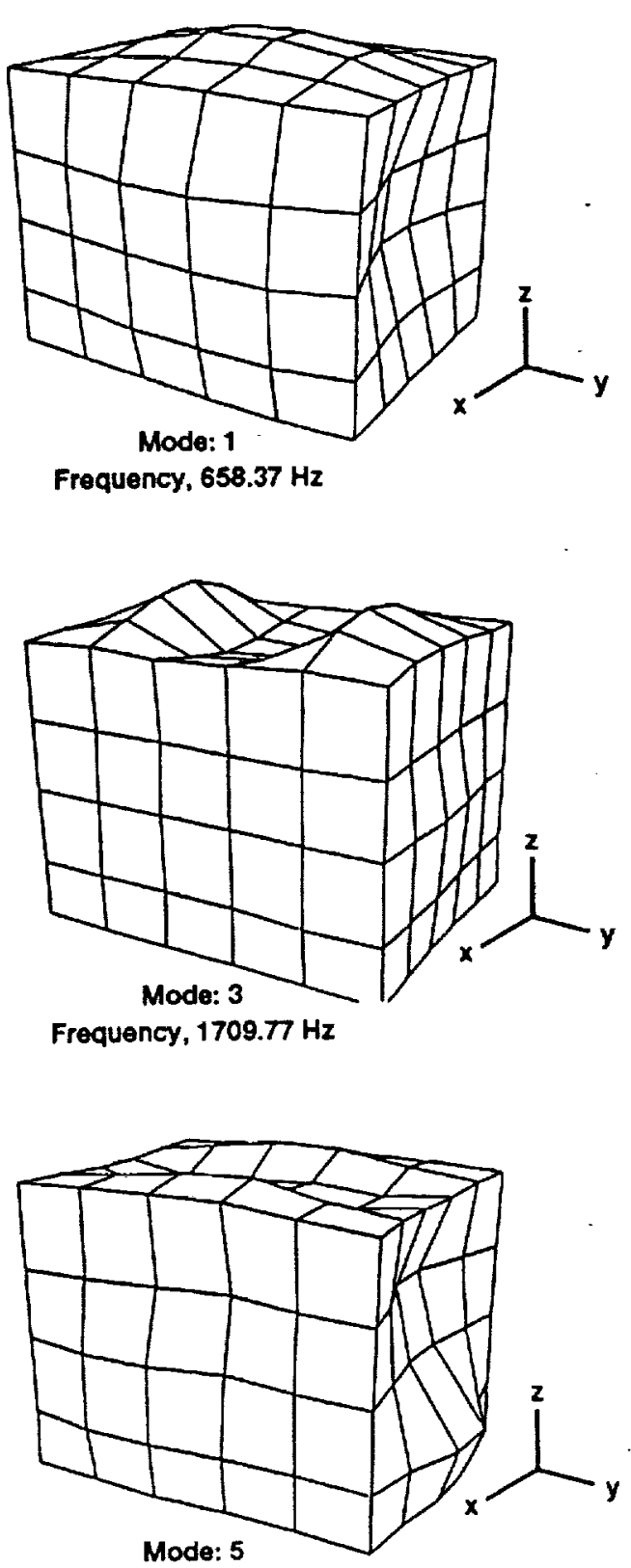

Frequency, $2275.69 \mathrm{~Hz}$

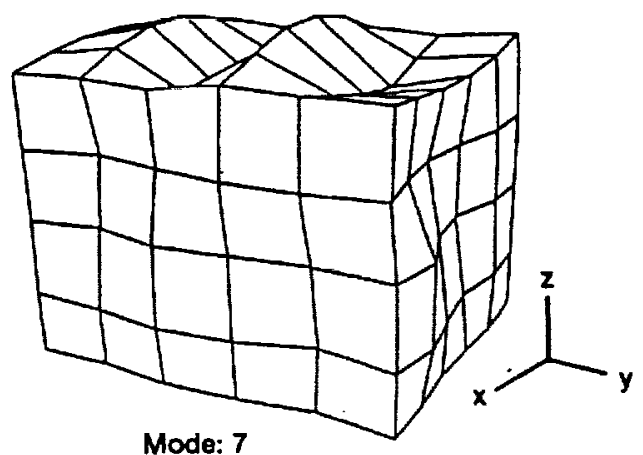

Frequency, $2722.16 \mathrm{~Hz}$

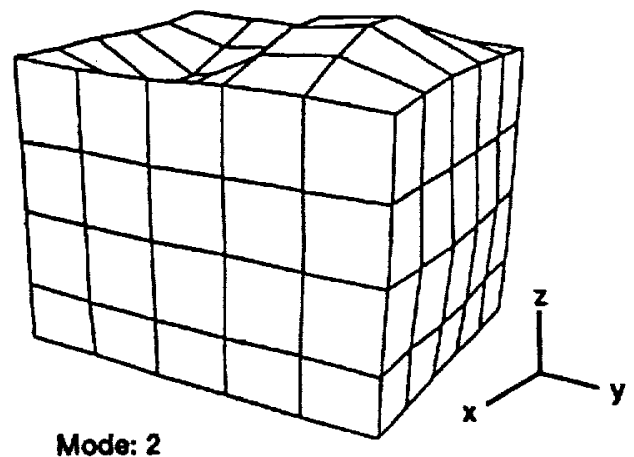

Frequency, $1048.56 \mathrm{~Hz}$

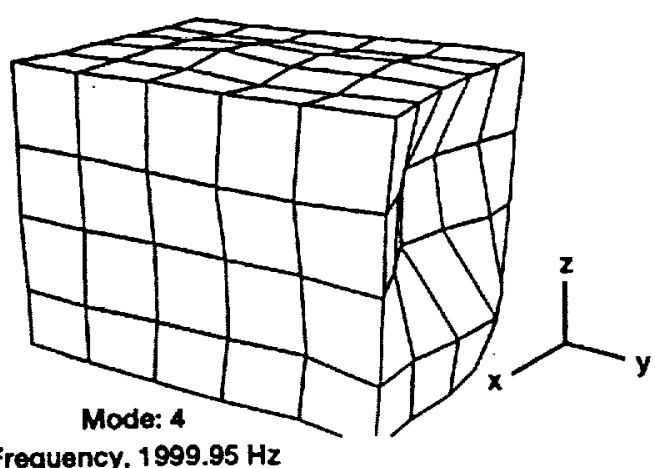

Frequency, $1999.95 \mathrm{~Hz}$

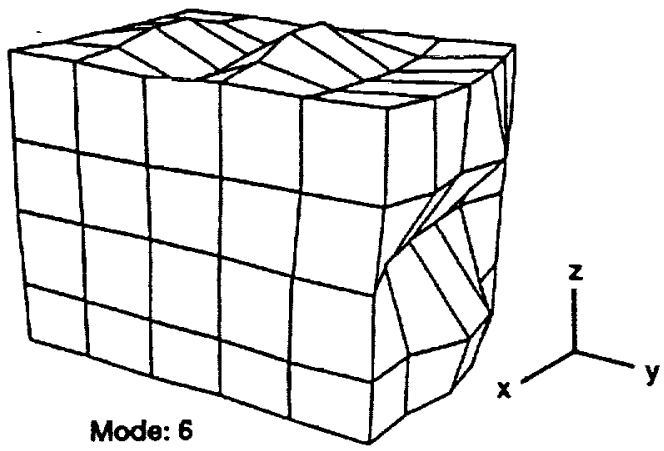

Frequency, $2535.77 \mathrm{~Hz}$

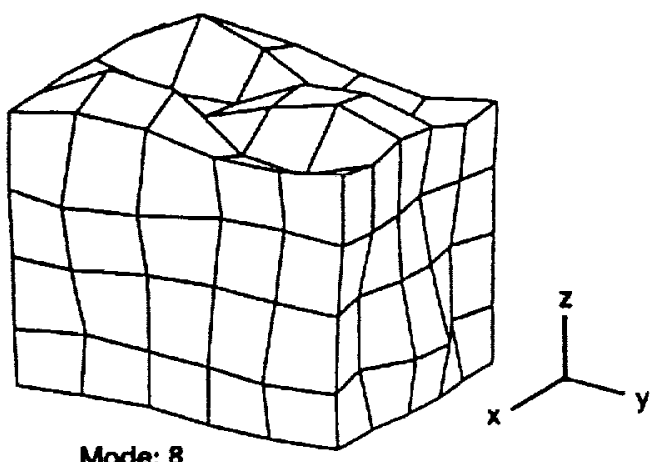

Mode: 8 Frequency, $2961.71 \mathrm{~Hz}$

Figure 4.- Gearbox experimental mode shapes.

10 


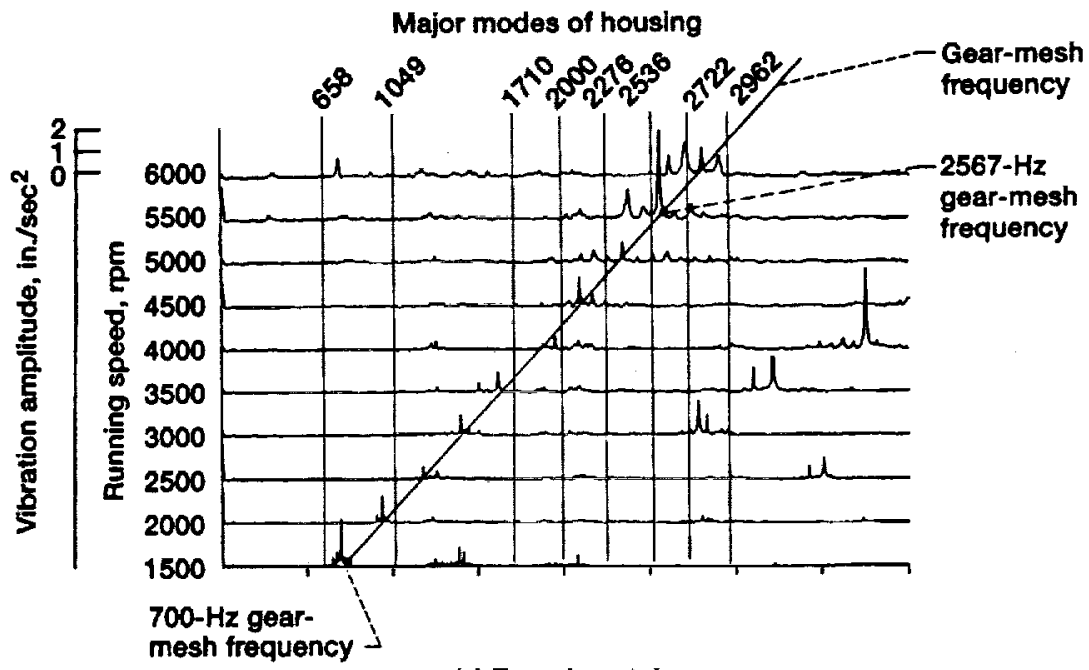

(a) Experimental.

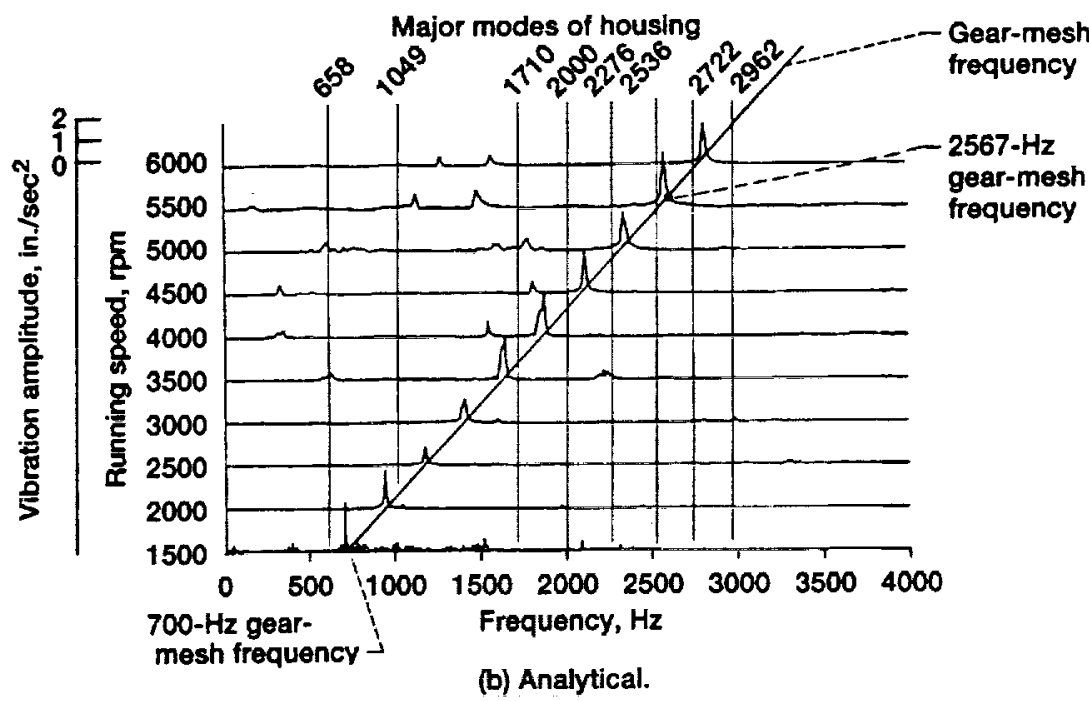

Figure 5.-X-direction experimental and analytical vibration frequency spectra of the gearbox 


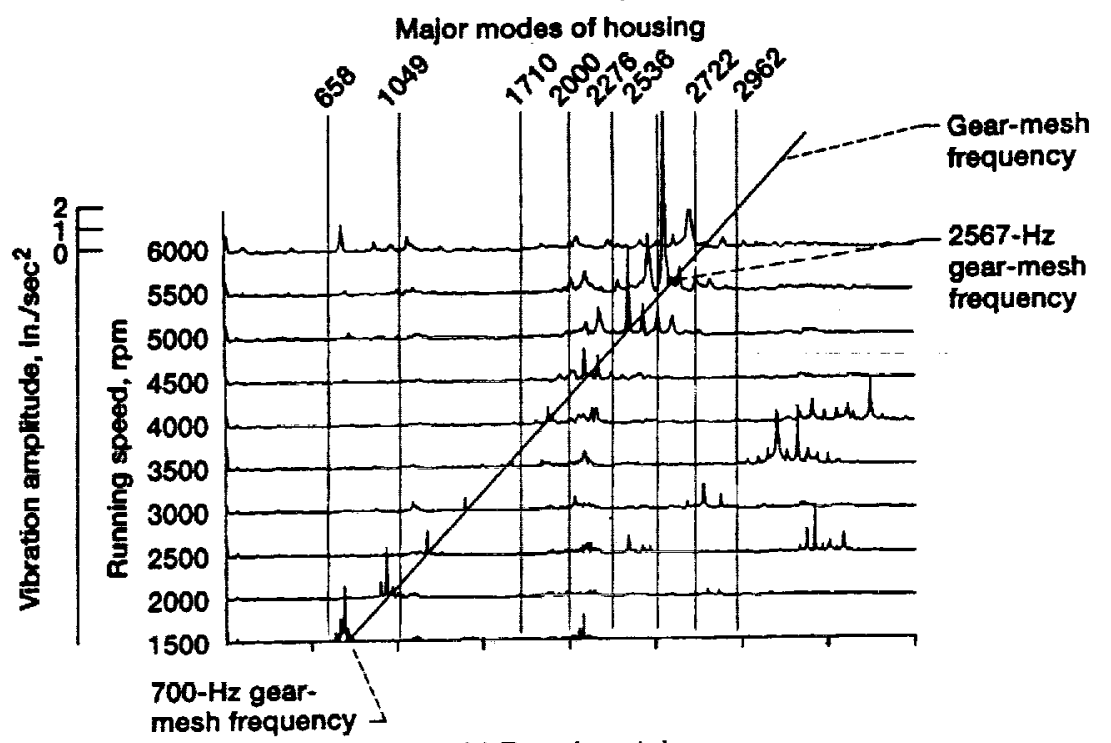

(a) Experimental.

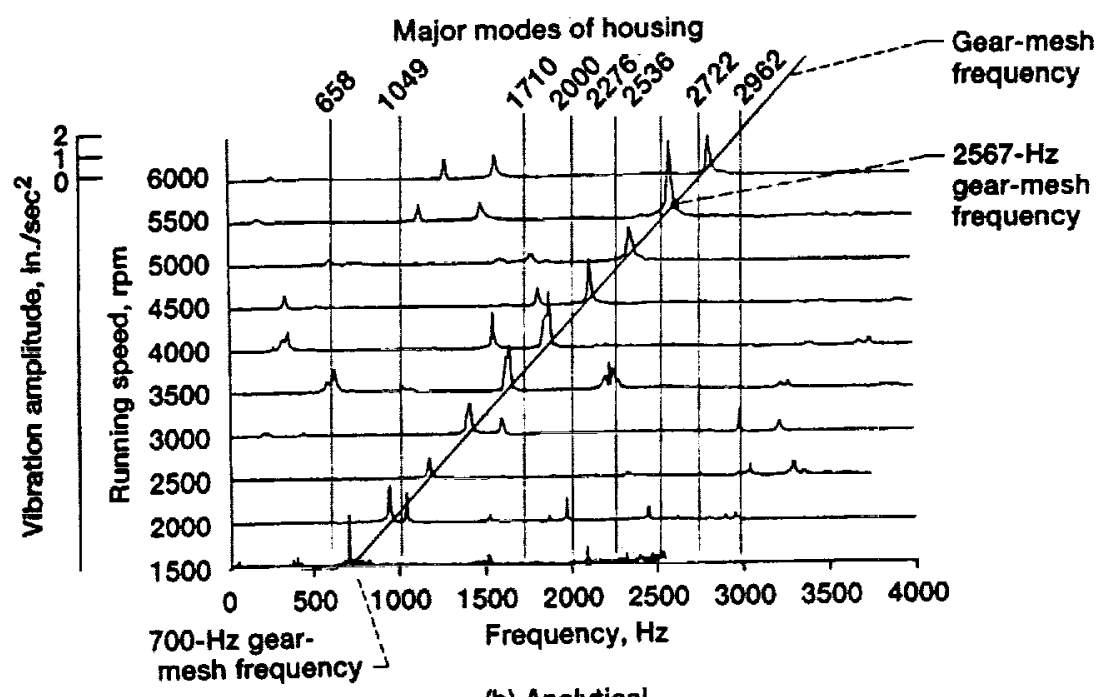

(b) Analytical.

Figure 6.-Y-direction experimental and analytical vibration frequency spectra of the gearbox. 


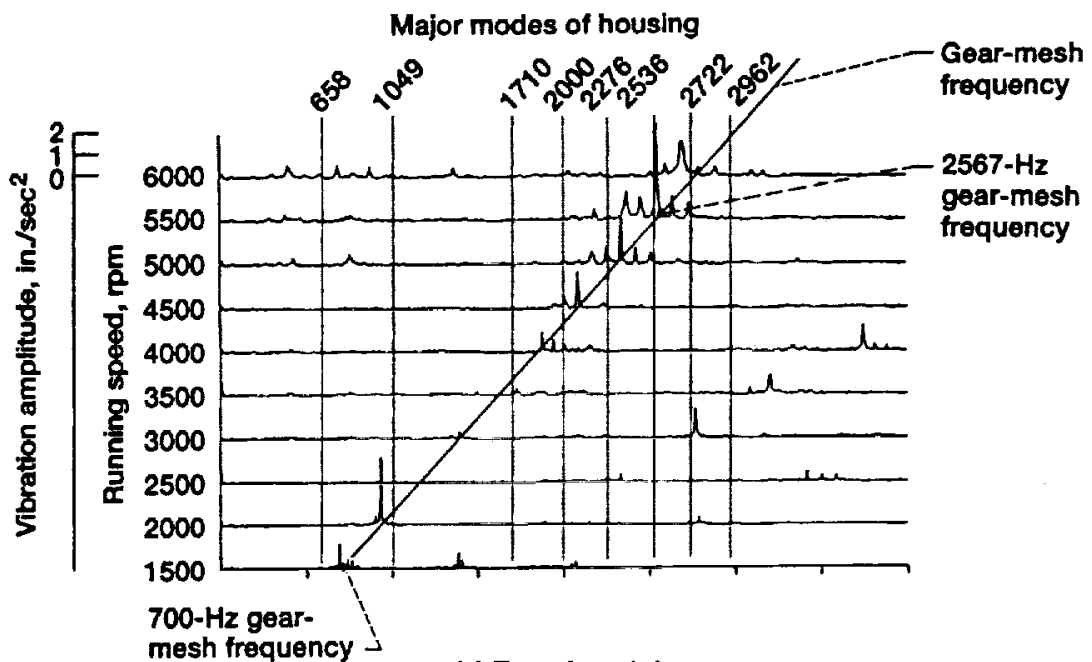

(a) Experimental.

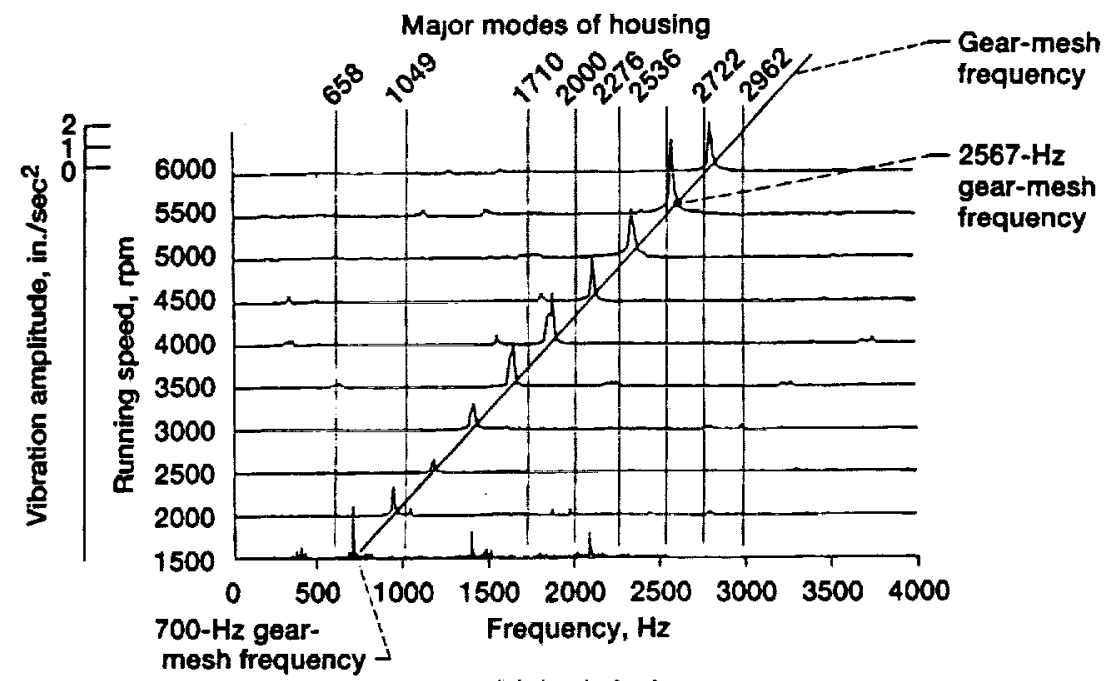

(b) Analytical.

Figure 7.-Z-direction experimental and analytical vibration frequency spectra of the gearbox. 


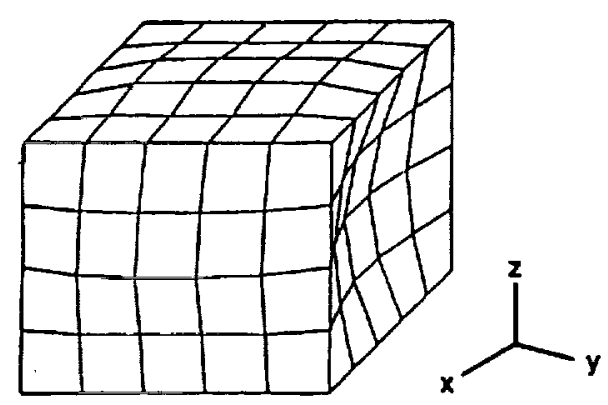

Mode: 1

Frequency $=658$

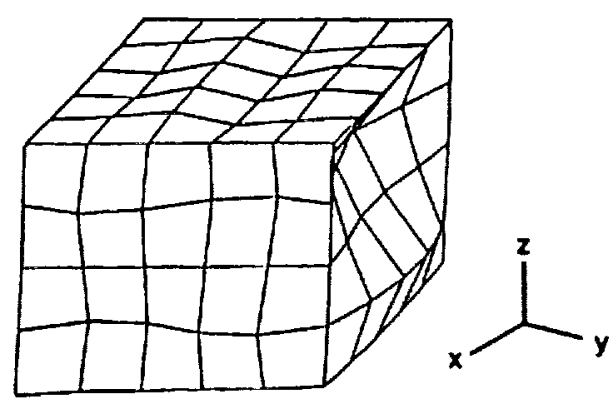

Mode: 3

Frequency $=1762$

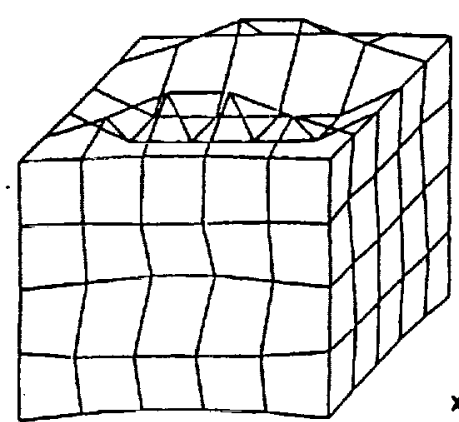

Mode: 5

Frequency $=2336$

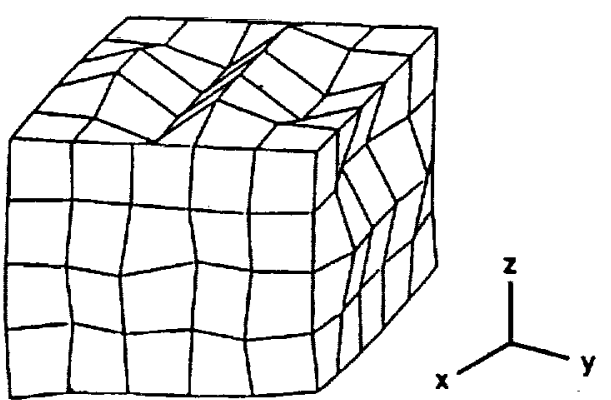

Mode: 7

Frequency $=2752$

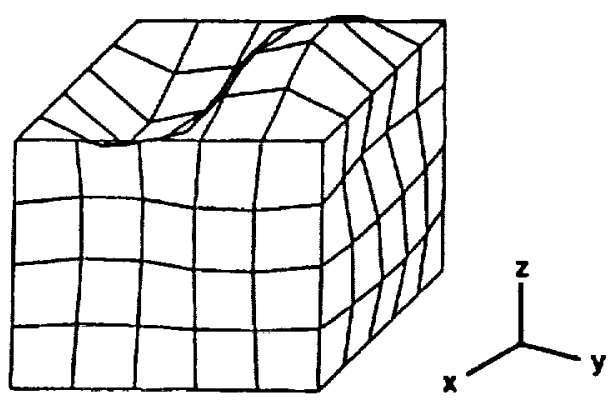

Mode: 2

Frequency $=1006$

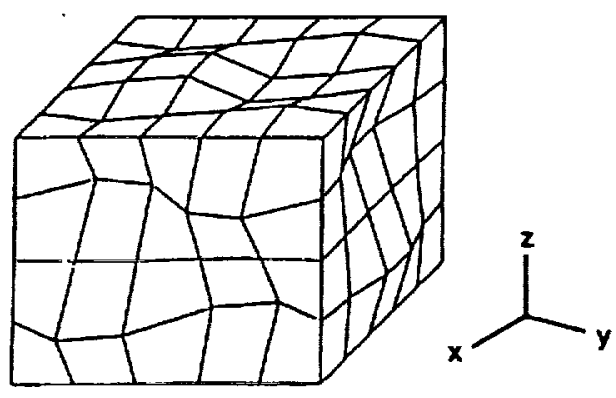

Mode: 4

Frequency $=2051$

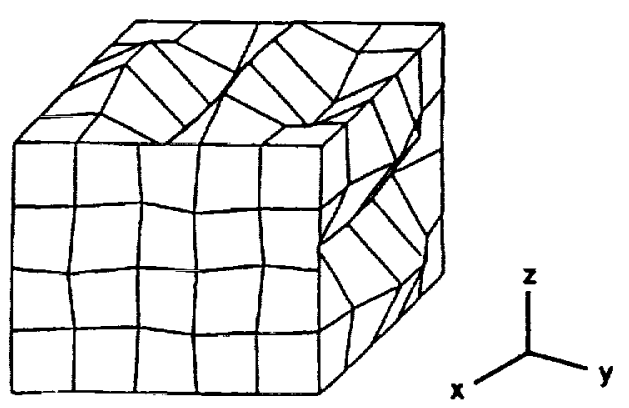

Mode: 6

Frequency $=2536$

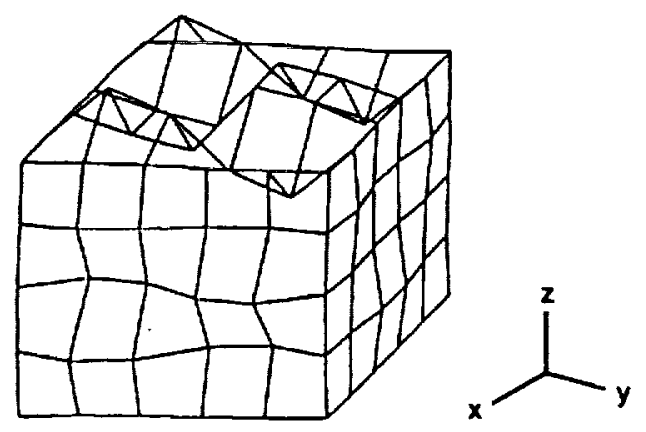

Mode: 8

Frequency $=3012$

Flgure 8.- Gearbox analytical mode shapes. 


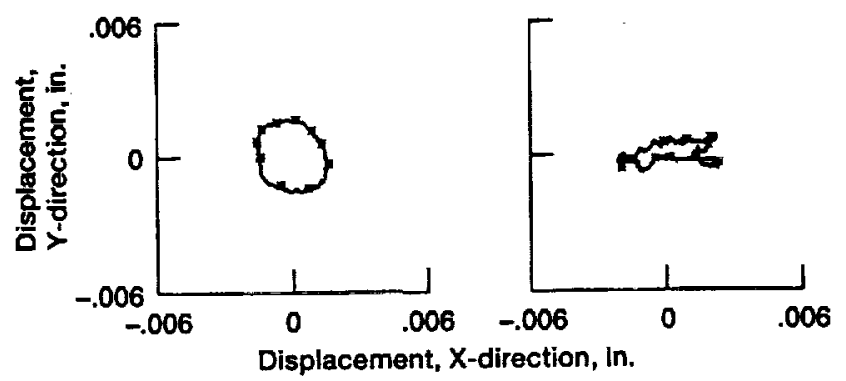

$\begin{array}{ll}\text { (a) Driving rotor orbit. } & \text { (b) Driven rotor orbit. }\end{array}$

Figure 9.-Orbital motion of rotor during slow roll. 


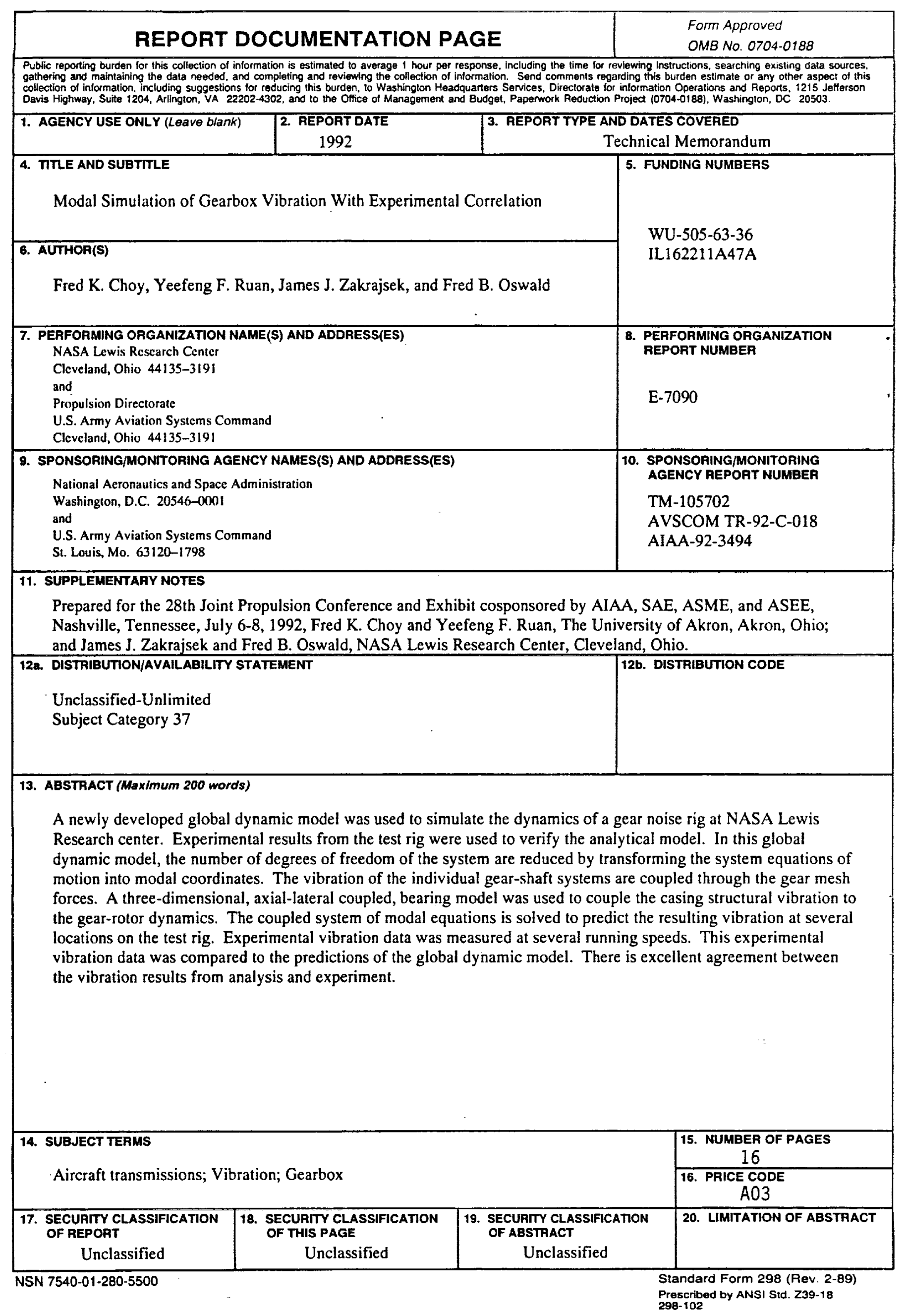

